\title{
Nghiên cứu ảnh hưởng của văn hóa doanh nghiệp đến sự cam kết gắn bó với tổ chức của nhân viên các ngân hàng thương mại trên địa bàn tỉnh Sóc Trăng
}

\section{Effects of business culture on the organizational commitment of employees at commercial banks in Soc Trang province}

\author{
Ngô Mỹ Trân ${ }^{*}$, Lý Ngọc Thiên Kim² ${ }^{2}$ Lê Trần Minh Hiếu ${ }^{3}$ \\ ${ }^{1}$ Trường Đại học Đại học Cần Thơ, Việt Nam \\ ${ }^{2}$ Trung tâm xúc tiến đầu tư và Hỗ trợ doanh nghiệp Sóc Trăng, Việt Nam \\ ${ }^{3}$ Trường Tiểu học Võ Trường Toản, Việt Nam \\ "Tác giả liên hệ, Email: nmtran@ @tu.edu.vn
}

THÔNG TIN

DOI: $10.46223 /$ HCMCOUJS. econ.vi.14.3.481.2019

Ngày nhận: 23/04/2019

Ngày nhận lại: 09/08/2019

Duyệt đăng: 12/08/2019

Tì khóa:

ngân hàng thương mại, sự cam kết gắn bó, văn hóa doanh nghiệp
TÓM TĂT 
Keywords:

business culture, commercial banks, organizational commitment culture on the organizational commitment of employees in Soc Trang commercial banks including training and development; (2) awards and recognition; (3) risk acceptance; (4) empowerment; communication; (6) group work; (7) decision making and (8) administrative policies. Based on these results, some administrative implications were proposed to improve the organizational commitment including constructing internal communication culture and making sure that a full and clear notice on policy changes related to employees in the bank is made. In addition, the commercial banks should pay due attention to training and development policy as well as a fair compensation policy.

\section{Giới thiệu}

Trong những năm gần đây, văn hóa doanh nghiệp được nhắc đến nhiều trong những nghiên cứu cả trong và ngoài nước. Văn hóa doanh nghiệp trở thành một triết lý quản trị, cách thức để cải thiện hoạt động tổ chức từ giao tiếp trong tổ chức đến cả tâm tư, tình cảm của nhân viên. Các nghiên cứu trước đây cho thấy rằng văn hóa doanh nghiệp là nhân tố quan trọng giúp giảm xung đột và là chất keo vô hình kết dính các thành viên trong tổ chức lại với nhau. Nghiên cứu về cách vận hành và xây dựng văn hóa doanh nghiệp và thu hút nhân lực đối với những công ty có thương hiệu tầm cỡ thế giới như HP, Motorola, Citybank, Unilever, Google... cho thấy rằng chính những giá trị vô hình từ văn hóa doanh nghiệp của các tổ chức này đã tạo thành những đặc điểm đặc trưng cốt lõi mang đến cho họ sự thu hút nguồn nhân lực mạnh mẽ mà bất kì nhân viên nào cũng mong muốn được làm việc trong các tổ chức này (Schein, 2010).

Sự gắn bó của nhân viên đối với tổ chức là đề tài được nhiều học giả quan tâm nghiên cứu. Sự gắn kết trong tổ chức mang một vai trò quan trọng, sự gắn kết này không những mang lại những nhân tố vô hình mà cũng mang lại nhiều lợi ích có thể định lượng được trong doanh nghiệp. Số liệu trong Marciano (2010) cho thấy những tổ chức có điểm gắn kết nhân viên cao có mức tăng trưởng thu nhập trên cổ phần tăng $28 \%$ và doanh thu tăng $19 \%$. Ngược lại, những tổ chức có điểm gắn kết nhân viên thấp có thu nhập cổ phần giảm $11 \%$ và doanh thu hoạt động giảm 32\%. Nghiên cứu của Towers Watson (2014) cũng khẳng định các tổ chức có sự gắn kết cao thu được tổng lợi nhuận trong vòng 5 năm nhiều hơn $13 \%$ so với các tổ chức có nhân viên thiếu gắn kết.

Ngành ngân hàng là một trong những ngành quan trọng của nước ta trong giai đoạn hiện nay. Năm 2016, hoạt động tài chính ngân hàng đóng góp 7,79\% trong tăng trưởng GDP toàn quốc. Ngành ngân hàng giữ một vị trí quan trọng trong việc ổn định sự phát triển kinh tế xã hội của cả nước nói chung và từng địa phương nói riêng. Trong những yếu tố đóng góp vào thành công của một doanh nghiệp thì nguồn nhân lực là một yếu tố rất được coi trọng. Đối với ngân hàng thương mại, yếu tố này càng trở nên quan trọng hơn vì đặc thù của hoạt động ngân hàng là kinh doanh dịch vụ chứ không phải sản phẩm hữu hình. Tuy nhiên, theo tình hình thực tế hiện nay, nhân sự của ngành ngân hàng đang gặp nhiều biến động. Theo nghiên cứu được tiến hành trong năm 2014 của Towers Watson, mức tăng lương trong năm 2013 của ngành ngân hàng là khoảng $10 \%$, trong khi tỷ lệ nghỉ việc lên tới $15 \%$, cao nhất trong số các ngành được 
khảo sát. Điều này cũng phần nào thể hiện được những khó khăn mà ngành ngân hàng đang phải đối diện. Không chỉ dừng lại ở lương thưởng, nhân viên ngành ngân hàng cũng đối diện với nhiều khó khăn, áp lực trong công việc về những chỉ tiêu và vô vàn những áp lực không tên khác.

Với tình trạng nhân viên ngân hàng nghỉ việc và nhảy việc hiện nay, các ngân hàng phải đau đáu bài toán nhân sự với tuyển dụng liên tục. Chi phí tuyển dụng và chi phí đào tạo đầu vào là một trong những vấn đề lớn và khó khăn cho các ngân hàng hiện nay. Xuất phát từ việc tìm kiếm lời giải cho bài toán nhân sự, những ngân hàng cũng không ngại tiến hành những dự án nghiên cứu khảo sát về sự hài lòng và gắn bó của nhân viên, điển hình là Viettinbank với dự án ESS khởi động vào cuối năm 2016 nhă̆m mục tiêu chính là xây dựng kế hoạch duy trì nguồn nhân lực, giảm thiểu rủi ro nhân sự, Dự án về xây dựng văn hóa doanh nghiệp và gắn kết nhân viên của $\mathrm{PV}$ combank và Công ty tư vấn chuyển đổi tổ chức $\mathrm{T} \& \mathrm{C}$ Consulting phối hợp thực hiện nhằm tạo lập giá trị riêng biệt cho ngân hàng và xây dựng nền tảng gắn kết nhân sự... Cùng với những khó khăn chung của ngành, bài toán nhân sự của tỉnh Sóc Trăng nói chung và của ngành ngân hàng tỉnh Sóc Trăng nói riêng vẫn là một câu hỏi khó. Vì thế, vấn đề về sự gắn kết của nhân viên trong ngành ngân hàng được đặt ra nhằm tìm ra được những nhân tố ảnh hưởng đến mức độ cam kết gắn bó với tổ chức của nhân viên ngân hàng. Ngoài những nhân tố về lương, thưởng thì những nhân tố về văn hóa doanh nghiệp ảnh hưởng thế nào đến sự gắn bó đó là vấn đề cấp bách cần được quan tâm nghiên cứu nhằm giải bài toán về nhân sự ngành ngân hàng của cả nước nói chung và của tỉnh Sóc Trăng nói riêng. Ngoài ra, có thể nói nghiên cứu khoa học về văn hóa doanh nghiệp ở Việt Nam nói chung và nghiên cứu về mối quan hệ giữa văn hóa doanh nghiệp và sự cam kết gắn bó của nhân viên tại các doanh nghiệp nói riêng còn khá mới mẻ, đặc biệt là trong lĩnh lực ngân hàng.

Những vấn đề đặt ra ở trên cho thấy việc thực hiện đề tài về sự ảnh hưởng của văn hóa doanh nghiệp đến sự cam kết gắn bó với tổ chức của nhân viên các ngân hàng thương mại (NHTM) trên địa bàn tỉnh Sóc Trăng là thật sự cần thiết. Ngoài việc cung cấp thêm bằng chứng thực nghiệm trong lĩnh vực nghiên cứu, kết quả nghiên cứu của đề tài này còn là tài liệu tham khảo cho các ngân hàng thương mại trong việc đề xuất chính sách liên quan đến văn hóa doanh nghiệp nhằm tăng cường sự cam kết gắn bó của nhân viên tại các ngân hàng trong thời gian tới.

\section{Cơ sở lý thuyết}

\subsection{Các khái niệm có liên quan}

\subsubsection{Khái niệm về văn hóa doanh nghiệp và sụ cam kết gắn bó}

\section{* Khái niệm về văn hóa doanh nghiệp}

Văn hóa doanh nghiệp thường được định nghĩa theo nhiều cách khác nhau bởi nhiều tác giả và các nhà nghiên cứu khác nhau. Trong nghiên cứu này, văn hóa doanh nghiệp được tiếp cận theo khái niệm của Schein (2010) và Lund (2003). Theo đó, văn hóa doanh nghiệp được xem là tổng hòa những giá trị, niềm tin, các mối quan hệ và quy tắc trong tổ chức, văn hóa công ty chính là nền tảng cho các hành vi và hoạt động của mỗi cá nhân trong tổ chức, là sản phẩm và tài sản của mỗi doanh nghiệp. Văn hóa doanh nghiệp tạo điều kiện cho tất cả các thành viên nhận ra được những sắc thái riêng mà một tổ chức muốn vươn tới, tạo ra sự cam kết tự nguyện đối với những gì vượt ra ngoài phạm vi niềm tin và giá trị của mối cá nhân. Chúng giúp các thành viên mới nhận thức được ý nghĩa của các sự kiện và hoạt động của tổ chức. 


\section{* Khái niệm về sư cam kết gắn bó}

Đã có nhiều nghiên cứu trước đây nghiên cứu về sự gắn bó với tổ chức. Kanter (1968) cho rằng: "Gắn bó với tổ chức như sự tự nguyện của người lao động để cống hiến năng lượng và sự trung thành với một tổ chức". Porter, Steers, Mowday, và Boulian (1974) định nghĩa cam kết gắn bó tổ chức của nhân viên được mô tả bằng ý định duy trì trong tổ chức, sự đồng thuận với các giá trị và mục tiêu của tổ chức. Sự gắn bó với tổ chức thể hiện ở tinh thần làm việc của nhân viên và những đóng góp của họ cho tổ chức. Kaldenberg, Becker, và Zvonkovic (1995) cho rằng "Gắn bó với tổ chức là sự sẳn lòng dành hết nỗ lực cho tổ chức, sự gắn bó chặt chẽ với tổ chức và tìm kiếm để duy trì mối quan hệ với tổ chức".

Định nghĩa khác của Mowday, Steers, và Porter (1979) về sự gắn bó tổ chức là sức mạnh đồng nhất của cá nhân với tổ chức và sự tham gia tích cực trong tổ chức; những nhân viên có sự gắn bó với tổ chức ở mức độ cao sẽ hài lòng hơn với công việc của họ, sẽ rất ít khi rời bỏ công việc và gắn bó với tổ chức hơn. Sự gắn bó với tổ chức là lời hứa của cá nhân đối với tổ chức bao gồm ý thức về gắn bó với công việc, lòng trung thành và niềm tin về các giá trị của tổ chức (O'Reilly \& Chatman, 1986). Theo Meyer và Allen (1991), "Cam kết gắn bó với tổ chức là trạng thái tâm lý biểu thị mối quan hệ của nhân viên với tổ chức, thể hiện sự gắn bó chặt chẽ với tổ chức và mong muốn góp phần vào việc hoàn thành các mục tiêu của tổ chức".

Nhìn chung, những định nghĩa trên cho thấy sự cam kết gắn bó với tổ chức thể hiện bằng ý định gắn bó lâu dài, mong muốn cống hiến với tổ chức đó, đồng thời cũng thể hiện sự tin tưởng, yêu mến, tự hào của nhân viên đối với doanh nghiệp của họ, cam kết gắn bó là động lực thúc đẩy họ làm việc chăm chỉ và nỗ lực hết mình bằng những kinh nghiệm và khả năng của bản thân, trung thành và cống hiến cho tổ chức.

\subsubsection{Lý thuyết nền có liên quan}

* Mô hình văn hóa doanh nghiệp của Recardo và Jolly (1997)

Theo Recardo và Jolly (1997), khi nói đến văn hóa công ty, người ta thường nói về hệ thống các giá trị và niềm tin được hiểu và chia sẻ bởi các thành viên trong một tổ chức. Một nền văn hóa giúp định hình và xác định các hành vi ứng xử của các thành viên và các chính sách trong tổ chức. Văn hóa doanh nghiêp được đo lường dựa trên tám khía cạnh bao gồm (1) Giao tiếp: số lượng và các hình thức giao tiếp, các thông tin gì được giao tiếp và bằng cách nào, có phải hệ thống giao tiếp mở; (2) Đào tạo và phát triển: Cam kết của các nhà quản trị cung cấp các cơ hội phát triển và tổ chức cho phép các kỹ năng mới để ứng dụng vào công việc. Bên cạnh đó, các nhà quản trị cung cấp các chương trình đào tạo cho nhu cầu phát triển hiện tại hay tương lai của nhân viên; (3) Phần thưởng và sự công nhận: Các hành vi nào thì được thưởng và các hình thức thưởng được sử dụng, các nhân viên được thưởng theo cá nhân hay theo nhóm; những tiêu chuẩn để thăng chức và mức độ mà tổ chức cung cấp phản hồi về mức độ hoàn thành công việc; (4) Ra quyết định: Ra quyết định liên quan đến các câu hỏi như các quyết định được tạo ra như thế nào và các mâu thuẫn được giải quyết ra sao; các quyết định nhanh hay chậm, tổ chức có mang tính đẳng cấp cao; việc ra quyết định là tâp trung hay phân quyền; (5) Chấp nhận rủi ro: Sự sáng tạo và cải tiển được đánh giá cao và tưởng thưởng; chấp nhận rủi ro được khuyến khích, có sự rộng mở với các ý tưởng mới; mọi người bị trừng phạt hay được khuyến khích để thử nghiệm các ý tưởng mới (6) Định hướng kế hoạch: Hoạch định dài hạn hay ngắn hạn và định hướng kế hoạch tương lai; các tầm nhìn, chiến lược, mục tiêu nào được chia sẻ với nhân viên; nhân viên cam kết ở cấp độ nào để đạt chiến lược của doanh nghiệp và các mục tiêu khác của tổ chức; (7) Làm việc nhóm: Khía cạnh này liên quan đến các vấn đề đó là tầm quan trọng, 
hình thức và sự hiệu quả của làm việc nhóm trong tổ chức. Nó bao gồm tầm quan trọng của sự hợp tác giữa các phòng ban khác nhau, sự tin tưởng giữa các bộ phận chức năng hay các đơn vị khác nhau và mức độ hỗ trợ đối với quá trình thực hiện công việc và (8) Các chính sách quản trị: Khía cạnh này đo lường sự công bằng và nhất quán với các chính sách được thực thi, sự ảnh hưởng của phong cách quản trị đối với nhân viên, mức độ nhà quản trị cung cấp một môi trường làm việc an toàn.

\section{* Mô hình RESPECT của Marciano (2010) về văn hóa doanh nghiệp và sụ gắn bó}

Marciano (2010) cho rằng gắn kết nhân viên là một điều rất quan trọng trong việc ổn định và phát triển tổ chức và nhân tố quyết định cho sự gắn kết này không phải chỉ là thưởng phạt như những lý thuyết trước đây đã nêu ra mà là các yếu tố về văn hóa doanh nghiệp đóng vai trò cốt lõi để mức độ gắn kết trở nên mạnh mẽ từ đó gia tăng lòng trung thành và sự nỗ lực, đóng góp của nhân viên cho tổ chức, xuất phát từ sự tôn trọng lẫn nhau trong tổ chức. Nhà nghiên cứu này đã đưa ra mô hình RESPECT về các yếu tố văn hóa doanh nghiệp tác động đến sự gắn kết nhân viên bao gồm 7 nhân tố là sự công nhận, sự trao quyền, phản hồi hỗ trợ, quan hệ hợp tác, sự mong đợi, sự chu đáo và sự tin tưởng.

\subsection{Giả thuyết nghiên cúu}

Trong các nghiên cứu trước đây về ảnh hưởng của văn hóa doanh nghiệp và cam kết gắn bó với tổ chức, nhiều tác giả đã sử dụng mô hình Recardo và Jolly (1997) trong các lĩnh vực khác nhau như công nghệ thông tin, giáo dục, tài chính... Có thể thấy được mô hình văn hóa doanh nghiệp của Recardo và Jolly (1997) có cái nhìn khá toàn diện và có thể áp dụng trong nhiều lĩnh vực khác nhau. Vì thế, trong nghiên cứu này, mô hình văn hóa doanh nghiệp với 8 nhân tố phát triển bởi Recardo và Jolly (1997) cũng được ứng dụng bao gồm giao tiếp trong công ty, đào tạo và phát triển, phần thưởng và sự công nhận, chấp nhận rủi ro bởi sáng tạo và cải tiến, làm việc nhóm, định hướng và kế hoạch tương lai, sự công bằng và nhất quán trong các chính sách quản trị, hiệu quả đưa ra quyết định. Bên cạnh đó, có bằng chứng cho thấy việc được tin tưởng và được trao quyền tham gia vào các quyết định của tổ chức sẽ tăng cường cam kết gắn bó của nhân viên trong nhiều lĩnh vực (Maister, 2012; Marciano, 2010; Pareek \& Purohit, 2018), do đó nhân tố sự trao quyền sẽ được bổ sung vào mô hình nghiên cứu.

\section{Giao tiếp trong tổ chức:}

Giao tiếp là thành tố quan trọng tạo nên sự chia sẻ kiến thức và kinh nghiệm của lãnh đạo - nhân viên, của các đồng nghiệp với nhau. Giao tiếp giúp tăng cường gắn kết giữa các cá nhân trong tổ chức. D. T. P. Nguyen, Huynh, và Le (2014) đã chỉ ra rằng giao tiếp giữ vai trò trong việc tăng cường sự yêu mến của nhân viên với tổ chức vì việc chia sẻ cả công việc và cuộc sống thường ngày giữa các đồng nghiệp tăng cường thêm mối quan hệ gắn bó. Theo Truong và Do (2012), giao tiếp được nhìn nhận là nhân tố quan trọng để cải thiện cam kết trong nhân viên thông qua việc chia sẻ thông tin và trao đổi kiến thức. Trong lĩnh vực ngân hàng, sự giao tiếp trong tổ chức là phương tiện để nhân viên trau dồi kinh nghiệm và hạn chế những lỗi trong quá trình làm việc, tăng cường giao tiếp và chia sẻ thông tin trong ngân hàng không chỉ giúp cho nhân viên cập nhật được những thông tin về công việc, trau dồi nghiệp vụ của bản thân mà còn tăng tình cảm gắn bó giữa các đồng nghiệp, giữa nhân viên và tổ chức.

H1: Giao tiếp trong tổ chức có tác động tích cực đến cam kết gắn bó của nhân viên trong các NHTM 


\section{D Đào tạo và phát triển}

Chính sách và cam kết của nhà quản trị về việc cung cấp cơ hội cho nhân viên được đào tạo và phát triển ở cấp độ cao hơn mang ý nghĩa quan trọng trong việc thúc đẩy và tăng cường cam kết gắn bó của nhân viên đó (Recardo \& Jolly, 1997). Cơ hội được đào tạo chuyên môn và phát triển đúng năng lực của mình là nhu cầu mà mỗi nhân viên đều mong muốn đạt được. Maister (2012) cũng cho rằng đào tạo và phát triển cấu thành nên động lực phấn đấu của nhân viên. Với những cơ hội và định hướng được báo trước, nhân viên gia tăng lòng trung thành và có mục tiêu lâu dài với tổ chức để phấn đấu thăng tiến. Phan (2011) khi nghiên cứu về lĩnh vực ngân hàng cho thấy công tác đào tạo để nâng cao trình độ chuyên môn là điều mà các nhân viên NHTM quan tâm đến. Trong thời đại hiện nay, thị trường tài chính - tín dụng luôn thay đổi chớp nhoáng, những chính sách tài chính thường xuyên được thay đổi, các quy trình thủ tục luôn cập nhật cho phù hợp với bối cảnh trong nước và quốc tế là điều kiện để nhu cầu được trau dồi chuyên môn của các nhân viên NHTM tăng cao, đồng thời việc học hỏi những kỹ năng và các kiến thức để phát triển bản thân cũng như tiền đề để thăng tiến cũng là điều mà các nhân viên các NHTM quan tâm. Do đó, cơ hội để học hỏi và phát triển rõ ràng, có định hướng tạo điều kiện cho nhân viên ngân hàng nỗ lực và phấn đấu, trung thành với tổ chức. các NHTM

H2: Đào tạo và phát triển có tác động tích cưc đến cam kết gắn bó của nhân viên trong

\section{$>$ Phần thưởng và công nhận}

Phần thưởng và sự công nhận là tiêu chuẩn để các nhân viên phấn đấu. Phần thưởng và sự công nhận là nhân tố để ghi nhận lại những phấn đấu, nỗ lực của nhân viên trong tổ chức, khuyến khích nhân viên tích cực đóng góp và cống hiến cho tổ chức. Đã có nghiên cứu ghi nhận ảnh hưởng có ý nghĩa tích cực của sự công nhận và phần thưởng đối với sự hài lòng công việc, tạo động lực cho nhân viên trong tổ chức. Đồng thời, phần thưởng và sự công nhận làm tăng cường sự trung thành và cam kết gắn bó của tổ chức khi họ thấy được những mục tiêu để thăng chức (Truong \& Do, 2012). Đây cũng có thể được xem là nhân tố quan trọng ảnh hưởng đến cam kết gắn bó của nhân viên tại các NHTM. Nhân tố này có thể có tác động trực tiếp và mạnh mẽ đến sự gắn bó của nhân viên. Mức lương, thưởng và sự công nhận hợp lý với những nỗ lực mà họ bỏ ra là việc cần được cân nhắc đối với một ngành có áp lực được coi là "khắc nghiệt" như ngành ngân hàng.

H3: Phần thưởng và công nhận có tác động tích cực đến cam kết gắn bó của nhân viên trong các NHTM

\section{$>$ Ra quyết định}

Quá trình ra quyết định của nhà quản trị có ảnh hưởng đến cam kết gắn bó của nhân viên trong tổ chức. Các hành động được quyết định thực hiện thế nào, cách giải quyết mâu thuẫn ra sao phản ánh sự chuyên nghiệp của nhà quản trị và tổ chức. Kim (2014) khẳng định rằng phong cách lãnh đạo của nhà quản trị ảnh hưởng tích cực đến hành vi của nhân viên trong tổ chức. Sự cam kết gắn bó sẽ tăng lên khi mức độ tích cực của nhà quản trị trong việc giải quyết các mâu thuẫn được nâng cao. Hadian (2017) cũng nêu cao vai trò của quyết định của người quản lý trong việc tạo lập sự tin tưởng của các cá nhân trong tổ chức.

H4: Ra quyết định có tác động tích cực đến cam kết gắn bó của nhân viên trong các 


\section{Chấp nhận rủi ro}

Sự sáng tạo và cải tiến là nhân tố được đánh giá cao trong nhiều nghiên cứu để tăng cường sự gắn bó của nhân viên với tổ chức. Với sự chấp nhận rủi ro để tiến hành những cải cách, nghiên cứu và chấp thuận những sáng kiến, sáng tạo, các ý tưởng mới của nhân viên tạo cho nhân viên sự khích lệ đóng góp ý kiến vào tổ chức. Nghiên cứu của Truong và Do (2012) cho thấy rằng chấp nhận rủi ro cho việc sáng tạo và cải tiến giữ vai trò quan trọng và tích cực trong việc tăng cường cam kết gắn bó của nhân viên, đặc biệt là trong lĩnh vực công nghệ thông tin và kỹ thuật. Tuy nhiên, trong các lĩnh vực ngành nghề khác, sáng tạo và cải tiến cũng đóng vai trò quan trọng như giáo dục và tài chính (Carville \& Sudha, 2016).

H5: Ra quyết định có tác động tích cực đến cam kết gắn bó của nhân viên trong các NHTM

\section{Định hướng kế hoạch}

Tầm nhìn dài hạn trong tổ chức có ý nghĩa quan trọng để xác định mục tiêu và sứ mệnh chung của tổ chức, đồng thời là kim chỉ nam để định hướng hành động của nhân viên trong tổ chức. Carville và Sudha (2016) cho thấy yếu tố dài hạn có ý nghĩa quan trọng trong sự tập trung của nhân viên. Một mục tiêu, định hướng kế hoạch khả thi, rõ ràng có ý nghĩa quan trọng trong việc tăng cường cam kết gắn bó của nhân viên. Phan (2011) cho thấy rằng tầm nhìn rõ ràng, dài hạn của lãnh đạo các NHTM sẽ tạo niềm tin cho nhân viên vào sự phát triển của ngân hàng trong tương lai, từ đó nhân viên luôn tích cực đóng góp vì mục tiêu lâu dài. Trong bối cảnh hiện nay, ngành ngân hàng có nhiều biến động, sự định hướng phát triển dài hạn càng quan trọng hơn để củng cố lòng tin của nhân viên vào ngân hàng để tăng cường cam kết.

H6: Định hương kế hoạch dài hạn có tác động tích cục đến cam kết gắn bó của nhân viên trong các NHTM

\section{> Làm việc nhóm}

Sự hợp tác và hỗ trợ trong công việc giữa các nhân viên với nhau có ý nghĩa quan trọng trong việc tăng cường cam kết tình cảm của nhân viên với tổ chức. Nhân tố này khá quan trọng và được nhắc đến trong nhiều mô hình như văn hóa hợp tác của Cameron và Quinn (2011), quan hệ hợp tác của Marciano (2010), sự cộng tác của Pareek và Purohit (2018), .. Làm việc theo nhóm tạo điều kiện tăng năng suất và hiệu quả của công việc. Nhiều nghiên cứu đã chứng minh rằng làm việc theo nhóm, năng suất và hiệu quả của mỗi cá nhân cao hơn hẳn năng suất và hiệu quả trung bình của mỗi cá nhân khi làm việc riêng lẻ. Trong lĩnh vực ngân hàng, sự hỗ trợ và tương tác giữa các khâu trong cùng bộ phận là hêt sức quan trọng. Làm việc nhóm là nhân tố để thúc đẩy năng suất chung. Sự phấn đấu và hỗ trợ lẫn nhau của các nhân viên ngân hàng nhằm đạt được mục tiêu chung là hết sức cần thiết và quan trọng trong môi trường cạnh tranh khốc liệt trong lĩnh vực ngân hàng hiện nay.

\section{NHTM}

H7: Làm việc nhóm có tác động tích cực đến cam kết gắn bó của nhân viên trong các

\section{> Chính sách quản trị}

Vai trò của nhà quản trị được đề cao trong nhiều nghiên cứu. Những chính sách đúng đắn, nhất quán và khả thi có thể giúp nhân viên an tâm và ở lại làm việc lâu dài với tổ chức. Nhân tố này đã được minh chứng trong nghiên cứu của Denison và Mishra (1995) và của Maister (2012). Nhân tố này còn được xem xét như là thước đo sự chuyên nghiệp của ngân 
hàng. Những chính sách quản trị công bằng, nhất quán xuyên suốt quá trình triển khai và thực hiện, được kỳ vọng có tác động vào lòng tin của nhân viên và sự tự hào của họ về tổ chức, tạo động lực phấn đấu và tăng cường cam kết.

H8: Chính sách quản trị nhất quán có tác động tích cục đến cam kết gắn bó của nhân viên trong các NHTM

\section{$>$ Sư trao quyền}

Tầm quan trọng của sự trao quyền được đề cập trong nghiên cứu Maister (2012) và Pareek (2003). Sự trao quyền thể hiện ở khả năng được tham gia, góp ý kiến vào các chính sách, kế hoạch của tổ chức, được tạo điều kiện thuận lợi khuyến khích sáng tạo. Yildirim, Acaray, và Candan (2016) cho rằng sự tham gia vào công tác quản lý có ý nghĩa quan trọng và theo chiều hướng tích cực trong việc tăng cường cam kết của nhân viên. Việc được tham gia vào công tác tổ chức và xây dựng chiến lược của công ty làm cho nhân viên cảm thấy tầm quan trọng của bản thân trong tổ chức. Họ cảm thấy có trách nhiệm với tổ chức, là một phần của tổ chức, từ đó làm tăng cường sự gắn bó với tổ chức hơn, khơi dậy sự tự nguyện cống hiến cho tổ chức. Trong bối cảnh các NHTM hiện nay, nhân tố này rất cần thiết trong việc tạo nên sự gắn bó của nhân viên. NHTM

H9: Sự trao quyền có tác động tích cực đến cam kết gắn bó của nhân viên trong các

\subsection{Mô hình nghiên cúu đề xuất}

Từ cơ sở lý thuyết được trình bày ở trên, mô hình nghiên cứu được đề xuất có 9 nhóm nhân tố (Hình 1) thuộc văn hóa tổ chức được kỳ vọng có ảnh hưởng đến sự cam kết gắn bó của nhân viên ngân hàng, cụ thể là (1) giao tiếp, (2) đào tạo và phát triển, (3) phần thưởng và công nhận, (4) ra quyết định, (5) chấp nhận rủi ro, (6) định hướng kế hoạch, (7) làm việc nhóm, (8) chính sách quản trị và (9) sự trao quyền. Trên cơ sở kế thừa những nghiên cứu trước đây, bộ thang đo của nghiên cứu được hình thành với 36 biến quan sát (được kết hợp trình bày trong Bảng 2 bên dưới để tiết kiệm không gian trình bày). Các biến quan sát được đo lường bằng thang đo Likert 5 mức độ bao gồm (1) Hoàn toàn không đồng ý; (2) Không đồng ý; (3) Trung bình; (4) Đồng ý và (5) Hoàn toàn đồng ý. Trước khi thực hiện phỏng vấn chính thức, việc phỏng vấn thử được thực hiện với 20 nhân viên ngân hàng có nhiều kinh nghiệm nhằm thực hiện những điều chỉnh trong bảng câu hỏi cho phù hợp hơn với bối cảnh nghiên cứu. 


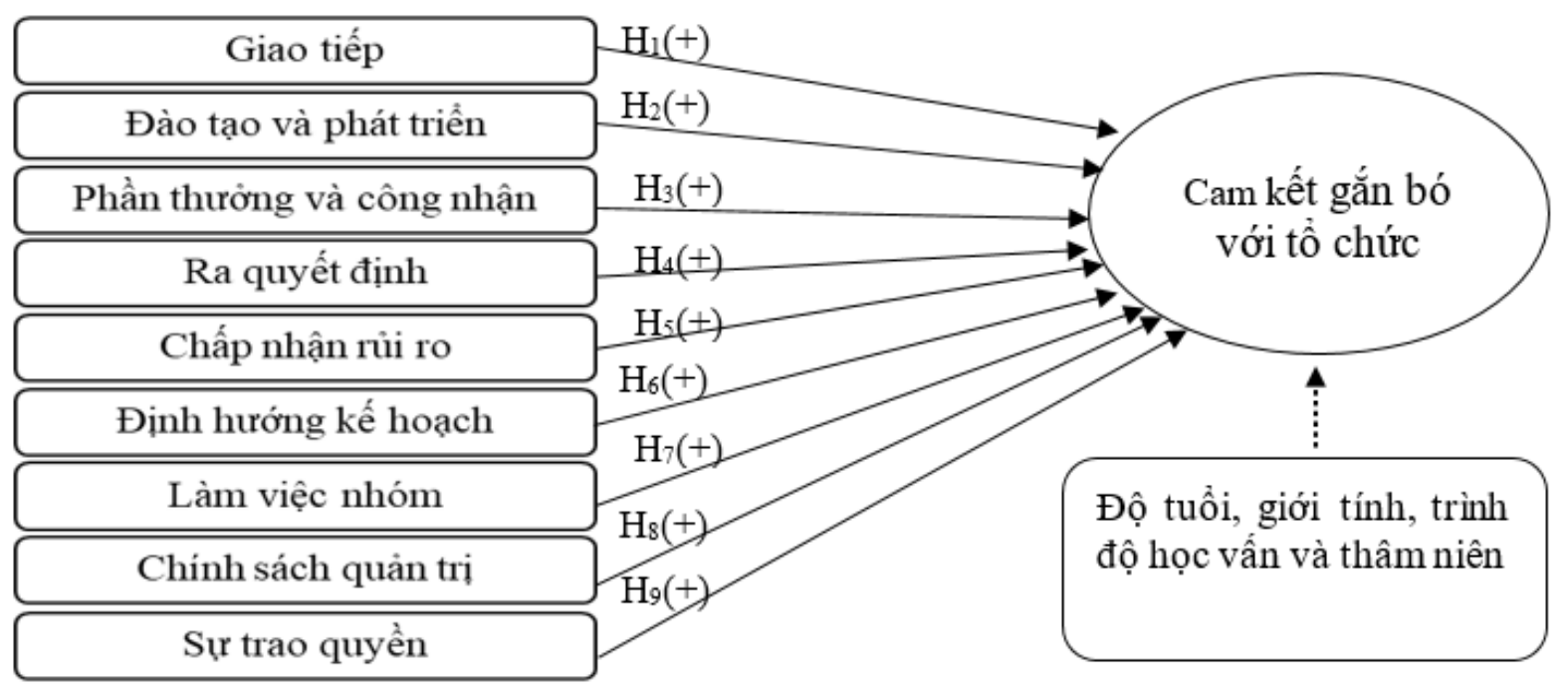

Hình 1. Mô hình nghiên cứu đề xuất

\section{Phương pháp nghiên cứu}

\subsection{Phương pháp thu thập số liệu}

Nghiên cứu tiến hành khảo sát dựa trên đối tượng là nhân viên các ngân hàng thương mại đang làm việc trên địa bàn tỉnh Sóc Trăng.

\section{Cõ̃ mẫu}

T. D. Nguyen (2011) cho rằng để sử dụng EFA, kích thước mẫu tối thiểu phải là 50 , tốt hơn là 100 và tî lệ quan sát so với biến đo lường là $5: 1$, nghĩa là 1 biến đo lường cần tối thiểu 5 quan sát, tốt nhất là tî lệ 10:1 trở lên. Đối với phương pháp hồi qui tuyến tính, công thức kinh nghiệm thường dùng là: $\mathrm{n} \geq 50+8 \mathrm{p}$ (với $\mathrm{n}$ là kích thước mẫu tối thiểu cần thiết và $\mathrm{p}$ là số lượng biến độc lập trong mô hình). Nghiên cứu sử dụng kết hợp cả 2 phương pháp phân tích EFA và hồi quy tuyến tính, cỡ mẫu được chọn trên nguyên tắc mẫu càng lớn càng tốt. Với 36 biến sử dụng trong phân tích nhân tố EFA, cỡ mẫu tối thiểu cần là 180 quan sát $(>=36 * 5)$.

\section{Phương pháp chọn mẫu}

Mẫu nghiên cứu được chọn theo phương pháp chọn mẫu thuận tiện, có phân tầng theo số lượng nhân viên tại các chi nhánh và phòng giao dịch của các ngân hàng thương mại nằm trong danh sách 10 ngân hàng thương mại uy tín nhất theo thống kê của Vietnam Report (2016) đang hoạt động tại địa bàn tỉnh Sóc Trăng. Dựa trên tỷ lệ nhân viên trên tổng số lượng nhân viên tại các chi nhánh và phòng giao dịch của các ngân hàng thương mại trên địa bàn tỉnh Sóc Trăng, số lượng quan sát phân tầng cho các ngân hàng được tính toán như trong Bảng 1 (với cỡ mẫu là 180 quan sát). 


\section{Bảng 1}

Cỡ mẫu dự kiến theo số lượng nhân viên tại các chi nhánh và phòng giao dịch của 10 ngân hàng thương mại uy tín nhất năm 2016 tại tỉnh Sóc Trăng

\begin{tabular}{|c|c|c|c|c|}
\hline Tên ngân hàng & $\begin{array}{c}\text { Số lượng chi nhánh } \\
\text { và phòng giao dịch } \\
\text { (tính đến tháng } \\
12 / 2016 \text { ) }\end{array}$ & $\begin{array}{c}\text { Tổng số } \\
\text { lượng } \\
\text { nhân viên }\end{array}$ & $\begin{array}{c}\text { Tỷ lệ } \\
\text { nhân } \\
\text { viên } \\
(\%)\end{array}$ & $\begin{array}{c}\text { Số lượng quan } \\
\text { sát dự kiến (=tỷ } \\
\text { lệ nhân } \\
\text { viền 180) }\end{array}$ \\
\hline $\begin{array}{l}\text { 1. Ngân hàng TMCP Công thương } \\
\text { Việt Nam (Vietinbank) }\end{array}$ & 4 & 120 & 16 & 28 \\
\hline $\begin{array}{l}\text { 2. Ngân hàng TMCP Đầu tý và } \\
\text { Phát triển Việt Nam (BIDV) }\end{array}$ & 2 & 182 & 24 & 43 \\
\hline $\begin{array}{l}\text { 3. Ngân hàng TMCP Ngoại thương } \\
\text { Việt Nam (Vietcombank) }\end{array}$ & 1 & 112 & 15 & 26 \\
\hline $\begin{array}{l}\text { 4. Ngân hàng TMCP Á } \\
\text { châu (ACB) }\end{array}$ & 1 & 55 & 7 & 13 \\
\hline $\begin{array}{l}\text { 5. Ngân hàng TMCP Kỹ thương } \\
\text { Việt Nam (Techcombank) }\end{array}$ & 1 & 65 & 9 & 15 \\
\hline $\begin{array}{l}\text { 6. Ngân hàng TMCP Quân đội } \\
\text { (MB) }\end{array}$ & 0 & 0 & 0 & 0 \\
\hline $\begin{array}{l}\text { 7. Ngân hàng TMCP Sài Gòn } \\
\text { thương tín (Sacombank) }\end{array}$ & 6 & 170 & 22 & 40 \\
\hline $\begin{array}{l}\text { 8. Ngân hàng TMCP Tiên phong } \\
\text { (TP bank) }\end{array}$ & 0 & 0 & 0 & 0 \\
\hline $\begin{array}{l}\text { 9. Ngân hàng TMCP Sài Gòn-Hà } \\
\text { Nội (SHB) }\end{array}$ & 1 & 60 & 8 & 14 \\
\hline $\begin{array}{l}\text { 10. Ngân hàng TMCP Sài Gòn } \\
\text { (Saigon Bank) }\end{array}$ & 0 & 0 & 0 & 0 \\
\hline
\end{tabular}

Nguồn: Tổng hợp từ VietNam Report (2016) và từ phòng nhân sự các NHTM trên địa bàn tỉnh Sóc Trăng

Với mỗi ngân hàng, tác giả chọn phỏng vấn trực tiếp tại các chi nhánh, phòng giao dịch, bằng việc liên hệ trước với phòng nhân sự và tiếp cận đối tượng khảo sát trước và sau giờ làm việc, đồng thời kết hợp với gởi bảng câu hỏi cho phòng nhân sự, phỏng vấn qua email, điện thoại với số lượng đáp viên là nhân viên của từng ngân hàng được trình bày theo Bảng 1 .

\subsection{Phương pháp phân tích số liệu}

- Một số chỉ tiêu thống kê mô tả như bảng phân phối tần số, số trung bình, số lớn nhất và số nhỏ nhất được sử dụng nhằm thống kê các đặc điểm nhân khẩu học của nghiên cứu, tổng hợp và thống kê các nhận định về các nhân tố văn hóa doanh nghiệp cũng như thống kê các chỉ tiêu về cam kết gắn bó.

- Độ tin cậy của thang đo được đánh giá bằng hệ số Cronbach’s Alpha.

- Phương pháp phân tích nhân tố EFA được sử dụng để gom nhóm các biến có cùng thuộc tính với nhau.

- Phương pháp phân tích hồi quy đa biến được sử dụng để ước lượng mức độ tác động của các nhân tố văn hóa doanh nghiệp ảnh hưởng đến cam kết gắn bó của nhân viên các ngân hàng thương mại tỉnh Sóc Trăng. Mô hình ước lượng được đề xuất như sau: 


$$
\mathrm{Y}=\alpha+\sum_{\mathrm{i}=1}^{\mathrm{n}} \beta_{\mathrm{i}} \mathrm{X}_{\mathrm{i}}+\varepsilon
$$

Trong đó:

- Y là biến đo lường sự cam kết gắn bó của nhân viên tại các ngân hàng thương mại trên địa bàn tỉnh Sóc Trăng

- $\mathrm{X}_{i}$ đại diện cho nhóm biến độc lập, đó là các nhân tố thuộc văn hóa doanh nghiệp được rút trích từ phương pháp phân tích nhân tố EFA, dự kiến gồm có các nhân tố như (1) sự giao tiếp, (2) đào tạo và phát triển, (3) phần thưởng và công nhận, (4) ra quyết định, (5) chấp nhận rủi ro, (6) định hướng kế hoạch, (7) làm việc nhóm, (8) chính sách quản trị và (9) sự trao quyền.

Ngoài ra, một số nghiên cứu trước đây cho thấy một số đặc điểm nhân khẩu học có ảnh hưởng đến sự cam kết gắn bó. Do đó, mô hình ước lượng được bổ sung một số biến kiểm soát, là một số nhân tố nhân khẩu học được kỳ vọng có ảnh hưởng đến cam kết gắn bó trong nghiên cứu này. Mô hình ước lượng lúc này được trình bày như sau:

$$
\mathrm{Y}=\alpha+\sum_{\mathrm{i}=1}^{\mathrm{n}} \beta_{\mathrm{i}} \mathrm{X}_{\mathrm{i}}+\sum_{\mathrm{j}=1}^{\mathrm{m}} \delta_{\mathrm{j}} \mathrm{D}_{\mathrm{j}}+\varepsilon
$$

Trong đó, $\mathrm{D}_{\mathrm{j}}$ đại diện cho nhóm biến kiểm soát bao gồm: (1) độ tuổi, (2) giới tính, (3) trình độ học vấn và (4) thâm niên công tác.

Độ tuổi (năm): Nhiều nhà nghiên cứu đã tìm ra mối quan hệ giữa độ tuổi và sự cam kết của nhân viên. Các nghiên cứu của Luthans, McCaul, và Dodd (1985); Mathieu và Zajac (1990); và Lok và Crawford (1999) cho thấy rằng có sự tương quan đáng kể giữa tuổi tác và sự cam kết gắn bó của nhân viên. Những nhân viên càng lớn tuổi, cam kết gắn bó của họ với công việc càng cao. Đối với những người trẻ tuổi, họ thích thay đổi công việc, tìm kiếm công việc phù hợp với mình nên sự gắn bó với tổ chức có chiều hướng giảm. Những người lớn tuổi hơn cần sự ổn định và ít có sự thay đổi, dẫn đến việc cam kết gắn bó với công việc của họ được kỳ vọng cao hơn.

Giới tính (Biến giả, nhận giá trị 1 nếu là nhân viên nam và 0 nếu là nhân viên nữ): Giới tính được một số tác giả cho rằng có ảnh hưởng đến sự cam kết gắn bó với tổ chức. Mathieu và Zajac (1990) cho rằng phụ nữ có cam kết cao hơn với tổ chức, do họ có nhiều tình cảm, trách nhiệm cho gia đình hơn nam giới nên họ cần sự ổn định trong công việc để đảm bảo đời sống của mình. Một số tác giả khác lại cho rằng nam giới có sức khỏe hơn, chịu áp lực cao hơn trong công việc họ, điều này dẫn đến việc họ có những công việc tốt hơn, cơ hội và thu nhập cao hơn phụ nữ dẫn đến cam kết gắn bó của họ cao hơn (Aven, Parker, \& McEvoy, 1993; Dodd-McCue \& Wright, 1996; Kaldenberg et al., 1995).

Trình độ học vấn: Trình độ học vấn được đo lường dưới dạng biến giả, nhận giá trị 1 nếu nhân viên có trình độ sau đại học và 0 nếu nhân viên có trình độ đại học. Do đặc thù của ngành ngân hàng là nhân viên có trình độ cao (nhân viên được khảo sát trong nghiên cứu này chỉ có trình độ đai học và sau đại học). Theo nhiều nghiên cứu, trình độ học vấn có tác động tiêu cực đến cam kết gắn bó của nhân viên, chẳng hạn như nghiên cứu của Mathieu và Zajac (1990); Yildirim et al. (2016); và D. T. P. Nguyen et al. (2014). D. T. P. Nguyen (2014) cho rằng các nhân viên có trình độ học vấn càng cao càng có mong muốn thể hiện khả năng của bản thân mình cao hơn. Họ có xu hướng tìm cho mình công việc tốt nhất, đáp ứng tốt nhất với nhu cầu, nguyện vọng của họ, do đó, tình trạng nhảy việc ở các nhân viên này cao hơn và cam kết gắn bó với tổ chức của họ lại thấp. 
Thâm niên công tác: Thâm niên công tác được đo lường bằng số năm làm việc của nhân viên tại ngân hàng. Cam kết gắn bó thường mạnh hơn đối với các nhân viên có thời gian làm việc lâu trong tổ chức. Newstrom và Davis (1985) đã chỉ ra rằng có mối quan hệ đáng kể và tích cực giữa cam kết tổ chức và thời gian làm việc của nhân viên. Nghiên cứu này cho thấy một người làm việc lâu hơn trong tổ chức sẽ có nhiều tình cảm hơn đối với tổ chức của mình và tăng thêm tinh thần trách nhiệm, từ đó có sự gắn bó mạnh mẽ với tổ chức. Tương tự như vậy, nghiên cứu của Hadian (2017) cho thấy những nhân viên có thời gian làm việc lâu hơn trong tổ chức có mối quan hệ gắn bó hơn với công việc và mối quan hệ với đồng nghiệp, do đó, cam kết tình cảm của họ cao hơn.

\section{Kết quả và thảo luận}

\subsection{Kết quả phân tích EFA}

Sau khi độ tin cậy của thang đo được kiểm định ${ }^{1}$, còn lại 34 biến đủ điều kiện còn lại sẽ được tiếp tục đưa vào phân tích nhân tố khám phá EFA. Tác giả thực hiện phân tích nhân tố thông qua phép xoay Varimax 1 lần. Kết quả phân tích nhân tố EFA rút trích được 9 nhân tố được thể hiện trong Bảng 3.

\section{Bảng 3}

Kết quả phân tích nhân tố EFA các nhân tố văn hóa doanh nghiệp

\begin{tabular}{|c|c|c|c|c|c|c|c|c|c|}
\hline \multirow{2}{*}{ Biến quan sát } & \multicolumn{9}{|c|}{ Nhóm nhân tố } \\
\hline & F1 & F2 & F3 & F4 & F5 & F6 & F7 & F8 & F9 \\
\hline \multicolumn{10}{|l|}{ Đào tạo và phát triển } \\
\hline Ngân hàng luôn tạo điều & & & & & & & & & \\
\hline $\begin{array}{l}\text { kiện cho anh/ chị cơ hội } \\
\text { học tập, phát triển cá nhân }\end{array}$ & 0,924 & & & & & & & & \\
\hline $\begin{array}{l}\text { Các chương trình đào tạo } \\
\text { của Ngân hàng hiện nay là } \\
\text { phù hợp với công việc }\end{array}$ & 0,912 & & & & & & & & \\
\hline $\begin{array}{l}\text { Anh/ chị được đào tạo đầy } \\
\text { đủ các kỹ năng cần thiết } \\
\text { để thực hiện tốt công việc } \\
\text { của mình }\end{array}$ & 0,900 & & & & & & & & \\
\hline $\begin{array}{l}\text { Anh/ chi có nhiều cơ hội để } \\
\text { phát triển và thăng tiến } \\
\text { trong công việc }\end{array}$ & 0,893 & & & & & & & & \\
\hline \multicolumn{10}{|l|}{ Định huớng kế hoạch } \\
\hline Anh/ chị được các cấp quản & & & & & & & & & \\
\hline $\begin{array}{l}\text { lý chia sé thông tin vê mục } \\
\text { tiêu chiến lược của Ngân } \\
\text { hàng }\end{array}$ & & 0,899 & & & & & & & \\
\hline $\begin{array}{l}\text { Ngân hàng có các chiến } \\
\text { lược phát triển rõ ràng }\end{array}$ & & 0,885 & & & & & & & \\
\hline $\begin{array}{l}\text { Các cấp quản lý luôn hoạch } \\
\text { định trước những thay đổi } \\
\text { có thể tác động đên tình } \\
\text { hình kinh doanh của Ngân } \\
\text { hàng }\end{array}$ & & 0,882 & & & & & & & \\
\hline
\end{tabular}

${ }^{1}$ Do giới hạn về không gian trình bày nên phần mô tả mẫu nghiên cứu và kết quả chi tiết phần kiểm định độ tin cậy bằng Cronbach's Alpha sẽ được cung cấp khi được yêu cầu. 


\begin{tabular}{|c|c|c|c|c|c|c|c|c|c|}
\hline \multirow{2}{*}{ Biến quan sát } & \multicolumn{9}{|c|}{ Nhóm nhân tố } \\
\hline & F1 & F2 & F3 & F4 & F5 & F6 & F7 & F8 & F9 \\
\hline $\begin{array}{l}\text { Lãnh đạo Ngân hàng luôn } \\
\text { xây dựng mục tiêu rất cụ } \\
\text { thể để mọi người hướng } \\
\text { đến }\end{array}$ & & 0,844 & & & & & & & \\
\hline \multicolumn{10}{|l|}{$\begin{array}{l}\text { Phần thưởng và công } \\
\text { nhận }\end{array}$} \\
\hline $\begin{array}{l}\text { Anh/ chị được khen thưởng } \\
\text { và công nhận dựa trên } \\
\text { chất lượng công việc }\end{array}$ & & & 0,844 & & & & & & \\
\hline $\begin{array}{l}\text { Ngân hàng anh/chị có chính } \\
\text { sách khen thưởng và công } \\
\text { nhần công lao rất công } \\
\text { băng }\end{array}$ & & & 0,798 & & & & & & \\
\hline $\begin{array}{l}\text { Chính sách khen thưởng và } \\
\text { công nhận được truyền đạt } \\
\text { một cách rõ ràng đền } \\
\text { người lao động }\end{array}$ & & & 0,743 & & & & & & \\
\hline $\begin{array}{l}\text { Ngân hàng thực hiện các } \\
\text { chế độ khen thường đúng } \\
\text { như cam kết với nhân viên }\end{array}$ & & & 0,742 & & & & & & \\
\hline \multicolumn{10}{|l|}{ Chấp nhận rủi ro } \\
\hline $\begin{array}{l}\text { Anh/ chị được khuyến khích } \\
\text { thử các phương pháp khác }\end{array}$ & & & & & & & & & \\
\hline $\begin{array}{l}\text { so với những phương } \\
\text { pháp trước đây mọi người } \\
\text { đã làm }\end{array}$ & & & & 0,846 & & & & & \\
\hline $\begin{array}{l}\text { Anh/Chị được lãnh đạo chia } \\
\text { sẻ, động viên những cải } \\
\text { tiển không hiệu quả }\end{array}$ & & & & 0,815 & & & & & \\
\hline $\begin{array}{l}\text { Anh/chị được phép học hỏi } \\
\text { những sai lầm khi thực } \\
\text { hiện sự thay đổi mà không } \\
\text { bị khiển trách }\end{array}$ & & & & 0,812 & & & & & \\
\hline $\begin{array}{l}\text { Lãnh đạo luôn ủng hộ } \\
\text { anh/chị cả vật chất lâ̂n tinh } \\
\text { thần để thực hiện những ý } \\
\text { tưởng mới }\end{array}$ & & & & 0,789 & & & & & \\
\hline \multicolumn{10}{|l|}{ Sự trao quyền } \\
\hline $\begin{array}{l}\text { Anh/ chị được hỏi ý kiến vî̀ } \\
\text { việc loại bỏ hoặc thay đổi } \\
\text { các chính sách mà anh chị } \\
\text { cảm thấy hạn chế bởi } \\
\text { chúng }\end{array}$ & & & & & 0,831 & & & & \\
\hline $\begin{array}{l}\text { Anh/ chị có được hỏi ý kiến } \\
\text { để chấp nhận những rủi ro } \\
\text { mà Ngân hàng đang gặp } \\
\text { phải }\end{array}$ & & & & & 0,806 & & & & \\
\hline $\begin{array}{l}\text { Anh/chị được ủy quyền } \\
\text { trách nhiệm quyết định } \\
\text { trong các kế hoạch của } \\
\text { phòng/ Ngân hàng. }\end{array}$ & & & & & 0,760 & & & & \\
\hline $\begin{array}{l}\text { Anh/ chị được đề xuất các ý } \\
\text { kiến cá nhân về những }\end{array}$ & & & & & 0,721 & & & & \\
\hline
\end{tabular}




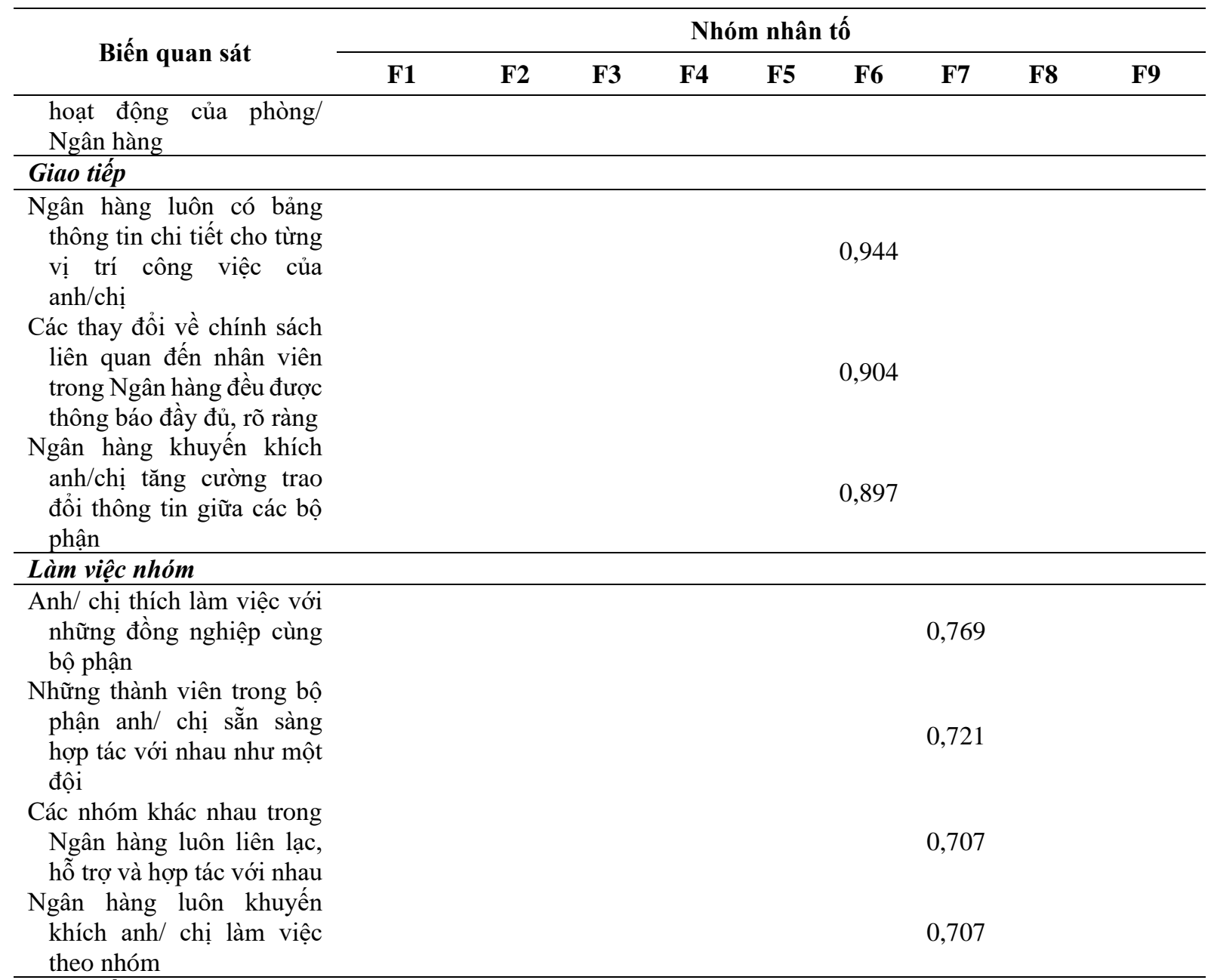

\section{Ra quyết định}

Ngân hàng thu thập nhiều nguồn thông tin và ý kiến phản hồi trước khi ra quyết định

Anh/chị được phép tham gia vào việc ra quyết định quan trọng của bộ phận

Các quyết định sáng suốt của cấp quản lý mang lại lợi ích lâu dài cho Ngân hàng

Anh/chị được tự do thực hiện công việc theo năng lực tốt nhất của mình

\section{Chính sách quản trị}

Các cấp quản lý luôn nhất quán trong việc thực thi các chính sách liên quan đến nhân viên

Các chính sách tuyển dụng, đào tạo, phát triển, khen thưởng trong Ngân hàng 


\begin{tabular}{lccccccccc}
\hline \multirow{2}{*}{ Biến quan sát } & \multicolumn{8}{c}{ Nhóm nhân tố } \\
\cline { 2 - 9 } & $\mathbf{F 1}$ & $\mathbf{F 2}$ & $\mathbf{F 3}$ & $\mathbf{F 4}$ & $\mathbf{F 5}$ & $\mathbf{F 6}$ & $\mathbf{F 7}$ & $\mathbf{F 8}$ & $\mathbf{F 9}$ \\
\hline là công bằng & & & & & & & & & \\
$\begin{array}{c}\text { Tiền lương và phân bổ thu } \\
\text { nhập giữa các thành viên } \\
\text { trong Ngân hàng là công } \\
\text { bằng }\end{array}$ & & & & & & & & \\
\hline Eigen values & 5,023 & 3,937 & 3,052 & 2,855 & 2,364 & 2,132 & 2,040 & 1,675 & 1,366 \\
Phương sai trích 9 nhân tốn & & $71,9 \%$ & & & & & & & \\
Hệ số KMO & & 0,720 & & & & & & & \\
Sig. của kiểm định Bartlett & & 0,000 & & & & & & & \\
\hline
\end{tabular}

Nguồn: Kết quả phân tích từ mẫu khảo sát gồm 180 nhân viên ngân hàng (2018)

- Kết quả phân tích nhân tố sự cam kết gắn bó với tổ chức của nhân viên các ngân hàng thương mại: Kiểm định $\mathrm{KMO}$ của nhân tố cam kết gắn bó đạt 0,872 nằm trong khoảng $0,5>\mathrm{KMO}>1$, Hệ số Sig. = 0,000 của kiểm định Bartlett cho biết mối tương quan giữa các biến quan sát có ý nghĩa thống kê. Tổng phương sai trích đạt $70,64 \%$ có nghĩa là 5 biến nhân tố này có thể giải thích được 70,64\% độ biến thiên của dữ liệu.

\section{Bảng 4}

Kết quả phân tích nhân tố EFA cam kết gắn bó

\begin{tabular}{lc}
\hline \multicolumn{1}{c}{ Biến quan sát } & Nhóm nhân tố \\
\cline { 2 - 2 } & $\mathbf{1}$ \\
\hline Anh/chị không có ý định thay đổi công việc khi có điều kiện thích hợp & 0,858 \\
Anh/chị rất trung thành, sằn sàng làm việc lâu dài với Ngân hàng & 0,849 \\
Anh/chị hoàn toàn tin tưởng vào mục tiêu phát triển của tổ chức & 0,840 \\
Anh/chị luôn cố gắng nâng cao kỹ năng làm việc để có thể cống hiến & 0,835 \\
nhiều hơn cho Ngân hàng & 0,821 \\
Anh/chị cảm thấy tự hào là nhân viên của Ngân hàng & 3,532 \\
\hline Eigen values & $70,64 \%$ \\
Phương sai trích & 0,872 \\
Hệ số KMO & 0,000 \\
Sig. của kiểm định Bartlett & \\
\hline
\end{tabular}

Nguồn: Kết quả phân tích từ mẫu khảo sát gồm 180 nhân viên ngân hàng (2018)

Như vậy, sau khi phân tích nhân tố EFA, có 9 nhân tố thuộc văn hóa doanh nghiệp được rút trích, tiếp tục được đưa vào sử dụng trong phương pháp phân tích hồi quy để kiểm định mức độ ảnh hưởng của các nhân tố này đến sự cam kết gắn bó của nhân viên các ngân hàng thương mại.

\subsection{Kết quả phân tích hồi quy}

Tác giả áp dụng phương pháp phân tích hồi quy OLS để ước lượng mô hình (1) và (2). Kết quả ước lượng được trình bày trong Bảng 5 . 


\section{Bảng 5}

Kết quả phân tích hồi quy đa biến

\begin{tabular}{|c|c|c|c|c|}
\hline \multirow[t]{2}{*}{ Biến độc lập } & \multicolumn{2}{|c|}{$\begin{array}{c}\text { Mô hình (1) } \\
\text { (không biến kiểm soát) }\end{array}$} & \multicolumn{2}{|c|}{$\begin{array}{c}\text { Mô hình (2) } \\
\text { (có biến kiểm soát) }\end{array}$} \\
\hline & Hệ số & VIF & Hệ số & VIF \\
\hline \multicolumn{5}{|l|}{ Hằng số } \\
\hline Đào tạo và phát triển & $0,357 * * *$ & 1,000 & $0,351 * * *$ & 1,055 \\
\hline Định hýớng kế hoạch & 0,026 & 1,000 & 0,040 & 1,085 \\
\hline Phần thýởng và sự công nhận & $0,278 * * *$ & 1,000 & $0,234 * * *$ & 1,047 \\
\hline Chấp nhận rủi ro & $0,250 * * *$ & 1,000 & $0,290 * * *$ & 1,028 \\
\hline Sự trao quyền & $0,111 * *$ & 1,000 & $0,090 * *$ & 1,038 \\
\hline Giao tiếp & $0,431 * * *$ & 1,000 & $0,439 * * *$ & 1,079 \\
\hline Làm việc nhóm & $0,163 * * *$ & 1,000 & $0,193 * * *$ & 1,029 \\
\hline Ra quyết định & $0,174 * * *$ & 1,000 & $0,150 * * *$ & 1,049 \\
\hline Chính sách quản trị & $0,348 * * *$ & 1,000 & $0,354 * * *$ & 1,227 \\
\hline Giới tính nam & & & 0,030 & 3,403 \\
\hline Tuổi & & & $-0,243 * * *$ & 1,242 \\
\hline Trình độ học vấn sau đại học & & & $0,086^{*}$ & 3,484 \\
\hline Thâm niên công tác & & & $0,352 * * *$ & 1,117 \\
\hline Giá trị $F$ của mô hình & 34,157 & & 28,978 & \\
\hline Hệ số R² & 0,644 & & 0,694 & \\
\hline Hệ số $\mathrm{R}^{2}$ hiệu chỉnh & 0,625 & & 0,670 & \\
\hline Giá trị Sig. của mô hình & 0,000 & & 0,000 & \\
\hline Hệ số d của kiểm định Durbin - Watson & 2,063 & & 2,027 & \\
\hline
\end{tabular}

\section{Kết quả mô hình hồi quy không có biến kiểm soát}

Kết quả phân tích hồi quy đa biến cho thấy đối với mô hình không có biến kiểm soát, mô hình (1), hệ số $\mathrm{R}^{2}$ của mô hình là $64,4 \%$, điều này có nghĩa là các nhân tố thuộc văn hóa doanh nghiệp giải thích được $64,4 \%$ sự biến thiên của biến cam kết gắn bó của nhân viên các ngân hàng thương mại. Trong 9 nhân tố thuộc văn hóa doanh nghiệp được đưa vào mô hình, có 8 nhân tố có tác động có ý nghĩa thống kê đến cam kết gắn bó của nhân viên ngân hàng thương mại bao gồm: đào tạo và phát triển, phần thưởng và sự công nhận, chấp nhận rủi ro, sự trao quyền, giao tiếp, làm việc nhóm, ra quyết định và chính sách quản trị. Trong đó, có 3 nhân tố có ảnh hưởng lớn nhất đến sự cam kết gắn bó của nhân viên ngân hàng là nhân tố giao tiếp, đào tạo và phát triển và chính sách quản trị. Sự tác động của các nhân tố cụ thể như sau:

(1) Đào tạo và phát triển: Nhân tố đào tạo và phát triển được tìm thấy có mối quan hệ tỉ lệ thuận với sự cam kết gắn bó. Điều này có ý nghĩa rằng khi nhân viên trong các ngân hàng thương mại được hưởng các chính sách đào tạo và phát triển rõ ràng, tương xứng với năng lực 
và sự nỗ lực của họ thì sự gắn bó của họ đối với ngân hàng càng cao. Kết quả này phù hợp với kết quả của các nghiên cứu trước, chẳng hạn như Phan (2011); Truong và Do (2012). Nhân tố đào tạo và phát triển có hệ số ước lượng cao thứ hai (sau nhân tố giao tiếp), điều này cho thấy nhân viên các ngân hàng thương mại ngày nay rất quan tâm đến những chính sách về trau dồi kỹ năng, nghiệp vụ để phát triển bản thân. Do đó, đây là một nhân tố văn hóa doanh nghiệp quan trọng mà mỗi ngân hàng thương mại cần quan tâm thực hiện để nâng cao sự cam kết gắn bó của nhân viên ngân hàng.

(2) Phần thưởng và sụ công nhận: Phần thưởng và sự công nhận được tìm thấy có ảnh hưởng tích cực đến cam kết gắn bó của nhân viên ngân hàng thương mại. Trong lĩnh vực ngân hàng, những khoản thưởng nóng, thưởng năm, thưởng quý, thưởng tháng và sự vinh danh các cá nhân xuất sắc là chính sách đóng vai trò rất quan trọng để giữ chân được nhân viên. Các nhân viên cần sự khích lệ và công nhận từ cấp lãnh đạo, điều này không chỉ là sự biểu dương về vật chất mà còn là tinh thần, tạo cho họ tâm lý tự hào rằng bản thân đã đạt được thành tựu hay cống hiến cho doanh nghiệp, từ đó, sự cam kết gắn bó của họ đối với ngân hàng đang công tác càng chặt chẽ hơn.

(3) Chấp nhận rủi ro: Kết quả ước lượng ở Bảng 5 cho thấy bằng chứng về sự ảnh hưởng tích cực của nhân tố chấp nhận rủi ro đến sự cam kết gắn bó với tổ chức của nhân viên ngân hàng. Khi nhân viên được khuyến khích thử những phương pháp làm việc khác so với những phương pháp trước đây đã làm, đồng thời được lãnh đạo chia sẻ những cải tiến, dù có hiệu quả hay không, được ủng hộ cả vật chất lẫn tinh thần để thực hiện những ý tưởng mới có vai trò quan trọng trong việc tăng cường sự cam kết gắn bó của nhân viên các ngân hàng. Khi được đưa ra những phương án cải cách hoặc khi những rủi ro của việc thay đổi, thái độ giải quyết sai lầm của lãnh đạo cởi mở sẽ tăng cường cam kết gắn bó của nhân viên ngân hàng thương mại.

(4) Sụ trao quyền: Nhân tố sự trao quyền có ý nghĩa thống kê ở mức $5 \%$ và có mối quan hệ tỉ lệ thuận với cam kết gắn bó. Sự trao quyền được tìm thấy có sự tác động đến sự cam kết gắn bó trong nhiều lĩnh vực khác nhau như lĩnh vực công (Kim, 2014), dịch vụ tài chính (Carville \& Sudha, 2016). Việc được toàn quyền chịu trách nhiệm, trình bày ý kiến và giải quyết tất cả những kế hoạch chính sách được giao phó làm cho nhân viên cảm thấy bản thân mình quan trọng với ngân hàng họ đang làm việc. Do đó, được đề xuất các ý kiến của mình và được lãnh đạo chấp nhận, đồng thời được trao quyền hạn để đề xuất những ý tưởng mới là những vấn đề được nhiều nhân viên ngân hàng quan tâm, điều này không những giúp họ thoát khỏi áp lực doanh số bị áp đặt mà còn tạo cơ hội cho họ tự nguyện cống hiến cho ngân hàng.

(5) Giao tiếp: Nhân tố giao tiếp là nhân tố có ảnh hưởng cao nhất đến sự cam kết gắn bó của nhân viên ngân hàng. Giao tiếp trong tập thể tạo mối quan hệ thân thiết giữa đồng nghiệp với nhau và tạo ra môi trường làm việc thoải mái, văn minh. Kết quả nghiên cứu này phù hợp với nghiên cứu của Do (2011) rằng giao tiếp là yếu tố quan trọng nhất. Đối với các nhân viên ngân hàng được khảo sát, họ cho rằng ngoài giờ làm việc, việc giao tiếp với đồng nghiệp cũng là một yếu tố quan trọng để xây dựng mối quan hệ tốt trong ngân hàng. Trong quá trình làm việc, sự trao đồi thông tin giúp cho nhân viên ngân hàng được thoải mái và đoàn kết hơn, thông qua việc xây dựng tình cảm giữa đồng nghiệp với nhau, họ xây dựng được sự cảm mến với ngân hàng đang làm việc, điều này tăng sự cam kết gắn bó của họ.

(6) Làm việc nhóm: Nhân tố làm việc nhóm được tìm thấy có mối liên hệ tỷ lệ thuận 
đối với sự cam kết gắn bó với tổ chức. Việc hợp tác để hoàn thành nhiệm vụ là rất quan trọng trong quá trình làm việc. Việc hoàn thành chỉ tiêu kinh doanh theo phòng ban, nhóm kinh doanh và sự chia sẻ thông tin trong nhóm là yếu tố quan trọng để nhân viên ngân hàng gắn bó với nhóm nói chung và với ngân hàng đang làm việc nói riêng. Đối tượng và thông tin khách hàng là yếu tố bí mật trong lĩnh vực ngân hàng, làm việc nhóm giúp khai thác tối đa hệ thống và tiếp nhận thêm nhiều nguồn thông tin khách hàng chia sẻ với nhau theo địa bàn phân công, giúp nhân viên giải tỏa áp lực. Làm việc nhóm còn tăng cường tình đoàn kết giữa từng bộ phận riêng lẻ, từ đó họ cảm thấy gắn bó hơn với tổ chức.

(7) Ra quyết định: Việc được hỏi ý kiến trước khi đưa ra các quyết định chung của phòng/ban hoặc của chi nhánh là điều mà các nhân viên quan tâm. Nhân tố ra quyết định được tìm thấy có tác động tích cực đến cam kết gắn bó của nhân viên ngân hàng thương mại ở mức ý nghĩa thống kê $1 \%$. Việc ra quyết định sáng suốt của lãnh đạo ảnh hưởng trực tiếp đến quyền lợi và trách nhiệm của các nhân viên ngân hàng thương mại. Vì vậy, đối với họ, trong công tác ra quyết định, đặc biệt là vấn đề về lương thưởng và phúc lợi cần phải công tâm và rõ ràng. Quyền được tham gia vào việc xây dựng những chỉ tiêu cụ thể có liên quan đến bản thân mình làm cho nhân viên cảm nhận được sự công bằng. Khi được thỏa mãn điều này, sự gắn bó của họ với ngân hàng cũng được tăng lên.

(8) Chính sách quản trị: Hệ số ước lượng của nhân tố chính sách quản trị có ý nghĩa thống kê ở mức $1 \%$ và có mối quan hệ tỉ lệ thuận với cam kết gắn bó. Trong các nghiên cứu trước đó, các chính sách quản trị của lãnh đạo có sự ảnh hưởng hầu như trong tất cả các lĩnh vực. Trong nghiên cứu này, đối với các ngân hàng thương mại, chính sách quản trị là nhân tố có mức độ ảnh hưởng cao thứ 3 trong mô hình (sau nhân tố giao tiếp và nhân tố đào tạo và phát triển). Các chính sách quản trị là điều mà các nhân viên ngân hàng quan tâm. Do đó, các quy chế, nội quy chung, khen thưởng và xử phạt, các chính sách về tuyển dụng, đào tạo, chính sách trả lương cần công bằng và nhất quán. Ngoài ra, cấp quản lý cần thông tin kịp thời và nhất quán trong việc thực hiện và ban hành các chính sách này. Khi ngân hàng có các chính sách quản trị rõ ràng và nhất quán, nhân viên sẽ tuân theo những quy tắc và chính sách mà họ cảm thấy phù hợp với bản thân, từ đó nâng cao cam kết gắn bó.

(9) Định hướng kế hoạch: Không có bằng chứng thống kê về sự ảnh hưởng của nhân tố định hướng kế hoạch đến cam kết gắn bó của nhân viên các ngân hàng thương mại trong nghiên cứu này. Điều này có thể là do phần lớn bộ phận nhân viên ngân hàng thương mại ở cấp thấp không quan tâm đến định hướng phát triển hay tầm nhìn và sứ mệnh chung của ngân hàng, họ cần mục tiêu cụ thể với bản thân trong ngắn hạn để đạt được KPI như mong muốn.

\section{Kết quả mô hình hồi quy có biến kiểm soát}

Mô hình ước lượng khi thêm biến kiểm soát được trình bày trong Bảng 5 . Hệ số của các biến kiểm soát đưa vào mô hình là độ tuổi và thâm niên công tác có ý nghĩa thống kê ở mức $1 \%$. Biến trình độ học vấn sau đại học có ý nghĩa thống kê ở mức $10 \%$. Hệ số $\mathrm{R}^{2}$ điều chỉnh tăng từ 0,625 ở Mô hình (1) lên 0,670 ở Mô hình (2). Điều này chứng tỏ rằng các biến kiểm soát khi đưa vào mô hình làm tăng tính giải thích của mô hình. Hệ số hồi quy của các biến độc lập trong mô hình có sự thay đổi khi mô hình có tính đến sự tác động của các biến kiểm soát, tuy nhiên mức độ dao động là không đáng kể. 
Kết quả ước lượng của mô hình (2) trong Bảng 5 cho thấy biến độ tuổi có hệ số ước lượng âm và có ý nghĩa thống kê ở mức $1 \%$. Điều đó cho thấy nhân viên càng lớn tuổi, nhân viên ngân hàng càng có xu hướng ít gắn bó hơn với tổ chức, điều này có nghĩa là họ đã tích lũy một số kinh nghiệm nhất định và không lo sợ tình trạng nhảy việc như những người ít tuổi, ít kinh nghiệm hơn trong ngân hàng.

Hệ số của biến thâm niên công tác có ý nghĩa thống kê ở mức ý nghĩa $1 \%$ và tỉ lệ thuận với cam kết gắn bó $(0,131)$. Kết quả này có nghĩa là thời gian làm việc tại ngân hàng hiện tại càng lâu, nhân viên càng gắn bó hơn với tổ chức. Khi thời gian tại tổ chức càng nhiều, họ càng tích lũy nhiều mối quan hệ cũng như lòng yêu mến tổ chức, quen với công việc và môi trường thân thuộc làm cho sự cam kết gắn bó của họ trở nên mạnh mẽ hơn.

Trình độ học vấn cũng được tìm thấy có mối quan hệ tỷ lệ thuận với sự cam kết gắn bó của nhân viên ở mức ý nghĩa $10 \%$. Điều này có nghĩa là nhân viên có trình độ học vấn sau đại học có cam kết gắn bó với tổ chức hơn các đáp viên có trình độ đại học. Với các ưu đãi và chính sách lương thưởng và thăng tiến theo trình độ thỏa đáng trong các ngân hàng thì những nhân viên có trình độ học vấn cao được thỏa mãn hơn, vì thế sự cam kết gắn bó của họ cao hơn đối với các đáp viên có trình độ học vấn thấp hơn.

Biến kiểm soát giới tính trong mô hình này không có ý nghĩa thống kê. Điều này có nghĩa là không có sự khác biệt về cam kết gắn bó của nhân viên nam và nhân viên nữ trong các ngân hàng thương mại.

\section{Kết luận}

Nghiên cứu này phân tích sự ảnh hưởng của văn hóa doanh nghiệp đến sự cam kết gắn bó với tổ chức của nhân viên các ngân hàng thương mại trên địa bàn tỉnh Sóc Trăng. Đề tài được tiến hành dựa trên mẫu nghiên cứu gồm 180 nhân viên đang làm việc tại các chi nhánh và phòng giao dịch của các ngân hàng thương mại ở Sóc Trăng. Từ việc lược khảo các mô hình lý thuyết và các nghiên cứu thực nghiệm trước đó, 9 nhóm nhân tố với 36 biến quan sát thuộc văn hóa doanh nghiệp được kỳ vọng có ảnh hưởng đến sự cam kết gắn bó của nhân viên ngân hàng. Sau khi kiểm định độ tin cậy của thang đo bằng hệ số Cronbach's Alpha, còn 34 biến quan sát đạt yêu cầu về độ tin cậy. Các biến quan sát còn lại được tiếp tục sử dụng trong phương pháp phân tích nhân tố EFA. Kết quả phân tích EFA rút trích được 9 nhóm nhân tố thuộc văn hóa doanh nghiệp bao gồm: (1) sự giao tiếp, (2) đào tạo và phát triển, (3) phần thưởng và công nhận, (4) ra quyết định, (5) chấp nhận rủi ro, (6) định hướng kế hoạch, (7) làm việc nhóm, (8) chính sách quản trị và (9) sự trao quyền.

Sau khi thực hiện phân tích hồi quy, kết quả phân tích cho thấy tất cả các nhân tố trong mô hình đều có ảnh hưởng đến sự cam kết gắn bó với tổ chức của nhân viên ngân hàng thương mại, ngoại trừ nhân tố định hướng kế hoạch. Trong đó, sự giao tiếp là nhân tố có sự ảnh hưởng cao nhất. Ngoài ra, kết quả nghiên cứu còn cho thấy các nhân tố như tuổi, thâm niên công tác và trình độ học vấn cũng có ảnh hưởng đến sự cam kết gắn bó của các nhân viên ngân hàng thương mại trên địa bàn tỉnh Sóc Trăng.

Dựa trên những bằng chứng thực nghiệm từ kết quả phân tích nhân tố và phân tích hồi quy, một số hàm ý chính sách nhằm tăng cường cam kết gắn bó với tổ chức của nhân viên các ngân hàng thương mại trên địa bàn tỉnh Sóc Trăng được đề xuất như sau: 


\section{Đối với chính sách đào tạo và phát triển}

Kết quả hồi quy cho thấy nhân tố chính sách đào tạo và phát triển là một trong những nhân tố có ảnh hưởng lớn nhất đến sự cam kết gắn bó của nhân viên. Kết quả phân tích EFA đối với nhân tố đào tạo và phát triển thuộc văn hóa doanh nghiệp cho thấy những khía cạnh cấu thành nên nhân tố này bao gồm cơ hội học tập, phát triển cá nhân của nhân viên; chương trình đào tạo của ngân hàng phù hợp, việc đào tạo những kỹ năng cần thiết để thực hiện công việc và cơ hội để phát triển và thăng tiến trong công việc. Do đó, để tăng cường sự cam kết gắn bó cho nhân viên, những hàm ý chính sách liên quan đến nhân tố chính sách và phát triển được đề xuất gồm có:

Các ngân hàng thương mại cần xây dựng chiến lược đào tạo, đào tạo lại nguồn nhân lực. Đặc biệt, với xu thế công nghệ hiện đại phát triển, việc cập nhật thông tin và biến động của môi trường kinh doanh luôn thay đổi, ngân hàng cần có kế hoạch đào tạo định kỳ để cập nhật những thông tin và biến đổi đó của thị trường. Đồng thời, các ngân hàng thương mại cần có chính sách đào tạo chuyên môn sâu qua những chuyên đề chuyên ngành cho từng bộ phận cụ thể nhằm giúp cho nhân viên hoàn thiện hơn nghiệp vụ chuyên môn.

Chính sách đào tạo của ngân hàng cần có sự công bằng và nhất quán, đúng mục đích, đúng đối tượng nhằm tạo ra mục tiêu cho nhân viên hướng tới để không ngừng hoàn thiện bản thân; tích cực, chủ động trong việc tham gia đào tạo và bày tỏ mong muốn của mình đối với nghiệp vụ chuyên môn mà họ đang quan tâm.

Liên kết với các đơn vị đào tạo có chuyên môn, có uy tín nhằm đưa ra lộ trình phát triển nguồn nhân lực đúng đắn và đưa ra được những chuyên đề về chuyên môn nghiệp vụ kịp thời và cấp thiết.

Đổi mới cơ chế thi đua, khen thưởng; xây dựng cơ chế thi đua, khen thưởng của ngân hàng dựa trên năng suất, chất lượng và hiệu quả công việc được giao, trên cơ sở đó đưa ra cơ chế phân phối tiền lương phù hợp nhằm động viên nhân viên làm việc có năng suất, chất lượng; khen thưởng xứng đáng đối với nhân viên có trình độ chuyên môn cao, đóng góp lớn đối với ngân hàng.

\section{Sụr giao tiếp}

Nhân tố sự giao tiếp của văn hóa doanh nghiệp được tìm thấy có ảnh hưởng tích cực nhất đến sự cam kết gắn bó. Do đó, nhà quản trị cần đảm bảo luôn có bảng thông tin chi tiết cho từng vị trí công việc, đảm bảo có sự thông báo đầy đủ, rõ ràng về các thay đổi chính sách có liên quan đến nhân viên trong ngân hàng. Bên cạnh đó, việc xây dựng mối quan hệ thân thiện giữa cấp trên và cấp dưới để giảm bớt khoảng cách quyền lực theo quan điểm Á Đông cần được quan tâm vì đây là một trong những cách thức để xây dựng môi trường giao tiếp hiệu quả, cần tăng cường sự cởi mở trong việc trao đổi, thảo luận công việc, khuyến khích đối thoại trực tiếp trong việc trình bày các vấn đề công việc và cá nhân để tránh tình trạng hiểu sai lệch thông tin và đạt được sự nhất trí cao trong nội bộ của tổ chức.

\section{Chính sách quản trị}

Nhân tố chính sách quản trị cũng là một trong những khía cạnh thuộc văn hóa doanh nghiệp có ảnh hưởng nhiều đến sự cam kết gắn bó. Do vậy, các chính sách quản trị trong ngân hàng cần công khai, minh bạch và công bằng, đặc biệt chính sách về tiền lương và đãi ngộ phải 
nhất quán trong việc ban hành và thực hiện. Việc xây dựng và đánh giá lương nhân viên cần được tổ chức định kỳ, chế độ cần tương xứng với năng lực và nỗ lực cống hiến của họ.

Lấy nhân viên làm trọng tâm trong việc xây dựng chính sách về nhân sự, nhà quản trị cần nhìn nhận tâm tư tình cảm của nhân viên nhằm xây dựng chính sách nhân sự phù hợp, đó là tiền đề để thu hút tuyển dụng cũng như tạo điều kiện để nhân viên thấy được những ưu điểm của tổ chức và từ những ưu điểm đó làm tăng cường cam kết gắn bó của mình, đây là một chính sách quan trọng cho từng ngân hàng trong bối cảnh thị trường lao động phức tạp như hiện nay.

\section{Phần thưởng và sụ công nhận}

Bằng chứng thực nghiệm cho thấy phần thưởng và sự công nhận là nhân tố cần được quan tâm để tăng cường sự cam kết gắn bó của nhân viên ngân hàng. Do vậy, lãnh đạo ngân hàng thương mại cần cân nhắc lựa chọn chính sách thưởng và công nhận sự đóng góp của nhân viên một cách hợp lý. Cần xây dựng tiêu chí đánh giá hiệu quả làm việc của nhân viên (KPI) cụ thể cho từng vị trí với những tiêu chuẩn và thang điểm rõ ràng để đánh giá đúng năng lực làm việc của từng cá nhân, từ đó có cơ chế lương thưởng phù hợp, cũng như xác định được những nhân viên có năng lực để có chính sách đãi ngộ thích hợp, tạo môi trường làm việc tốt để họ có cơ hội phát triển và gắn bó lâu dài. Đầu tư cơ sở hạ tầng công nghệ thông tin để có thể dễ dàng tính toán một cách chính xác và tự động các chỉ tiêu KPI.

Hệ thống khen thưởng và các hình thức công nhận sự cống hiến phải đảm bảo tính công bằng, minh bạch, phù hợp với tiêu chí đánh giá nhân viên, ngoài các chế độ bảo hiểm theo quy định như bảo hiểm xã hội, bảo hiểm y tế; nên có thêm các hình thức bảo hiểm khác nhý bảo hiểm nhân thọ, bảo hiểm tai nạn cho người lao động và chương trình tiết kiệm tích luỹ dành cho nhân viên làm việc lâu năm và có những thành tích xuất sắc.

\section{Chấp nhận rủi ro}

Các ngân hàng cần khuyến khích nhân viên đưa ra các ý tưởng sáng tạo, cải cách trong quá trình làm việc, đồng thời cân nhắc việc áp dụng các ý tưởng một cách có sáng tạo vào tình hình thực tế để giải quyết công việc cách hiệu quả. Thường xuyên đánh giá tình hình hoạt động kinh doanh nhằm rút kinh nghiệm những thiếu sót kịp thời, cùng với việc tiếp thu phản hồi từ những vấn đề được đưa ra từ nhân viên, từ đó nhận định được những tồn tại còn thiếu sót và phát huy những điểm mạnh của cá nhân và tập thể trong từng bộ phận. Có các biện pháp khen thưởng khuyến khích các quan điểm cải tiến hiệu quả và chia sẻ, khuyến khích động viên những nhân viên chưa có cải tiến hiệu quả tiếp tục kiên trì đóng góp ý kiến.

Thường xuyên tổ chức các cuộc thi về sáng kiến kinh nghiệm trong nội bộ để khuyến khích tư duy sáng tạo và tư duy phản biện. Những cuộc thi này không những là nơi giải tỏa căng thẳng của nhân viên mà còn là nơi khuyến khích ý tưởng sáng tạo cho việc tìm ra và ứng dụng các cách giải quyết vấn đề mới vào các vấn đề còn tồn động, về các khâu dịch vụ còn nhiều phàn nàn của ngân hàng, từ đó nhận ra được các cá nhân ưu tú, đánh giá đúng năng lực của nhân viên.

\section{Sục trao quyền}

Ngân hàng cần tạo điều kiện để nhân viên nói lên tâm tư, nguyện vọng của mình, khuyến khích nhân viên thực hiện việc tự đặt KPI phù hợp, thay vì chỉ định họ thực hiện những phần việc cụ thể, nhà quản trị các ngân hàng có thể định hướng cho nhân viên bằng việc đặt ra các 
câu hỏi định hướng nhằm giúp cho họ giải quyết các vấn đề trong quá trình thực hiện công việc. Ban lãnh đạo các ngân hàng cần truyền đạt đến nhân viên về tầm nhìn của doanh nghiệp một cách rõ ràng và chỉ can thiệp vào các quyết định của nhân viên khi cần thiết để đảm bảo các quyết định ấy không mâu thuẫn hay xung đột với tầm nhìn chung.

\section{Làm việc nhóm}

Định hướng tổ chức thành lập các nhóm kinh doanh được trao quyền quyết định của riêng mình để tạo lập tinh thần đồng đội, tương hỗ trong việc đặt ra chỉ tiêu nhóm và phương pháp hoàn thành chỉ tiêu thích hợp. Cung cấp hỗ trợ cho các nhóm kinh doanh khi có các dự án quan trọng. Yêu cầu họ thách thức hiện trạng và lối tư duy thông thường nhằm khai thác tối đa sức mạnh của tập thể và tìm ra những đổi mới chất lượng trong công việc.

Huấn luyện chéo cho nhân viên là cách để các bộ phận khác nhau hiểu được văn hóa làm việc của ngân hàng không có sự ngăn cách giữa cách phòng ban, từ đó nhân viên sẽ có khuynh hướng đưa ra quyết định có lợi cho công ty trên phương diện tập thể, chứ không chỉ bộ phận của họ. Điều này cho nhân viên có cái nhìn khái quát hơn về các bộ phận khác nhau trong ngân hàng, đồng thời giúp họ nâng cao nghiệp vụ và hiểu rõ các vấn đề khác, từ đó giải quyết công việc giữa các phòng ban khác nhau trở nên thuận lợi hơn.

\section{Ra quyết định}

Thực hiện các khảo sát trong nội bộ trước khi ra những quyết định quan trọng là điều các ngân hàng nên xem xét. Những quyết định có ảnh hưởng trực tiếp đến quyền lợi và trách nhiệm của nhân viên cần được quan tâm xem xét đúng mức. Việc khảo sát không những là động thái làm hài lòng đại đa số nhân viên mà còn là biện pháp để tìm ra những ý kiến mới hợp lý cho những vấn đề của tổ chức.

Quá trình ra quyết định cần minh bạch, công khai và theo quy trình hợp lý, điều này có thể giúp tránh được những phản hồi trái chiều và tạo nên sự đồng thuận cao nhất trong tổ chức, giúp cho nhân viên hiểu được quy chế hoạt động của ngân hàng và tuân thủ những chính sách, quy chế mới áp dụng vào quá trình làm việc.

\section{Tài liệu tham khảo}

Aven, F. F., Parker, B., \& McEvoy, G. M. (1993). Gender and attitudinal commitment to organizations: A meta analysis. Journal of Business Research, 26(1), 63-73.

Cameron, K. S., \& Quinn, R. E. (2011). Diagnosing and changing organizational culture: Based on the competing values framework. Hoboken, NJ: John Wiley \& Sons.

Carville, S. P., \& Sudha, K. S. (2016). Impact of organizational culture on organizational commitment: A comparative analysis between the education and financial services sectors. International Journal of Education and Management Studies, 6(1), 40-47.

Denison, D. R., \& Mishra, A. K. (1995). Toward a theory of organizational culture and effectiveness. Organization Science, 6(2), 204-223.

Do, H. H. (2011). Vận dụng văn hoá doanh nghiệp vào việc xây dưng và phát triển thuong hiệu mang đậm đà bản sắc dân tộc cho các doanh nghiệp Việt Nam [Applying corporate 
culture to building and developing brands imbued with national identity for Vietnamese businesses]. Hanoi, Vietnam: NXB Đại học Kinh tế quốc dân.

Dodd-McCue, D., \& Wright, G. B. (1996). Men, women, and attitudinal commitment: The effects of workplace experiences and socialization. Human Relations, 49(8), 1065-1091.

Hadian, D. (2017). The relationship organizational culture and organizational commitment on public service quality; perspective local government in Bandung, Indonesia. International Review of Management and Marketing, 7(1), 230-237.

Kaldenberg, D. O., Becker, B. W., \& Zvonkovic, A. (1995). Work and commitment among young professionals: A study of male and female dentists. Human Relations, 48(11), 1355-1377.

Kanter, R. M. (1968). Commitment and social organization: A study of commitment mechanisms in utopian communities. American Sociological Review, 33(4), 499-517.

Kim, H. (2014). Transformational leadership, organizational clan culture, organizational affective commitment, and organizational citizenship behavior: A case of South Korea's public sector. Public Organization Review, 14(3), 397-417.

Lok, P., \& Crawford, J. (1999). The relationship between commitment and organizational culture, subculture, leadership style and job satisfaction in organizational change and development. Leadership \& Organization Development Journal, 20(7), 365-374.

Lund, D. B. (2003). Organizational culture and job satisfaction. Journal of Business \& Industrial Marketing, 18(3), 219-236.

Luthans, F., McCaul, H. S., \& Dodd, N. G. (1985). Organizational commitment: A comparison of American, Japanese, and Korean employees. Academy of Management Journal, 28(1), 213-219.

Maister, D. H. (2012). Managing the professional service firm. New York, NY: Simon and Schuster.

Marciano, P. L. (2010). Carrots and sticks don't work: Build a culture of employee engagement with the principles of respect. New York, NY: McGraw Hill Professional.

Mathieu, J. E., \& Zajac, D. M. (1990). A review and meta-analysis of the antecedents, correlates, and consequences of organizational commitment. Psychological Bulletin, 108(2), 171-194.

Meyer, J. P., \& Allen, N. J. (1991). A three-component conceptualization of organizational commitment. Human Resource Management Review, 1(1), 61-89.

Mowday, R. T., Steers, R. M., \& Porter, L. W. (1979). The measurement of organizational commitment. Journal of Vocational Behavior, 14(2), 224-247.

Newstrom, J. W., \& Davis, K. (1985). Human behavior at work: Organizational behavior. New York, NY: McGraw-Hill.

Nguyen, D. T. P. (2014). Động lực làm việc của nhân viên: Nghiên cưu truờng hợp động lục làm việc của nhân viên khối văn phòng ở Việt Nam [Work motivation of employees: Case study of office workers' working motivation in Vietnam]: Research report. Can Tho, Vietnam: Đại học Cần Thơ. 
Nguyen, D. T. P., Huynh, L. T. C., \& Le, T. T. T. (2014). Các yếu tố tác động đến sự gắn kết tổ chức của nhân viên khối văn phòng Cần Thơ [Factors affecting the organizational cohesion of Can Tho office workers]. Tạp chi Khoa hoc truò̀ng Đại hoc Cần Tho, 30, 9299.

Nguyen, T. D. (2011). Phwơng pháp nghiên cúu khoa hoc trong kinh doanh [Scientific research method in business]. Ho Chi Minh, Vietnam: NXB Tài chính.

O'Reilly, C. A., \& Chatman, J. (1986). Organizational commitment and psychological attachment: The effects of compliance, identification, and internalization on prosocial behavior. Journal of Applied Psychology, 71(3), 492.

Pareek, U. (2003). Training instruments in HRD and OD (2nd ed.). New Delhi: Tata McGrawHill Publishing Company Limited.

Pareek, L. U., \& Purohit, S. (2018). Training instruments in HRD and OD. New Delhi, India: SAGE.

Phan, L. T. M. (2011). Nghiên cứu về sự hài lòng công việc của các nhân viên trong các ngân hàng thương mại trên địa bàn Thừa Thiên - Huế [Research on job satisfaction of employees in commercial banks in Thua Thien - Hue]. Tạp chí Khoa hoc và Công nghẹ, 3(44), 186-192.

Porter, L. W., Steers, R. M., Mowday, R. T., \& Boulian, P. V. (1974). Organizational commitment, job satisfaction, and turnover among psychiatric technicians. Journal of Applied Psychology, 59(5), 603.

Recardo, R., \& Jolly, J. (1997). Organizational culture and teams. SAM Advanced Management Journal, 62(2), 4-7.

Schein, E. H. (2010). Organizational culture and leadership. Hoboken, NJ: John Wiley \& Sons.

Towers Watson. (2014). Nghiên cúu lục luợng lao động toàn cầu [Research the global workforce]. Retrieved March 11, 2019, from https://www.towerswatson.com/enVN/Insights/Newsletters/Asia-Pacific/vietnam-ban-tin/2014/Vietnam-2014-GlobalWorkforce-Study-at-a-Glance-Towers-Watson

Truong, L. H., \& Do, V. T. T. (2012). Ảnh hưởng của văn hóa công ty đến sự cam kết gắn bó của nhân viên: Trường hợp của công ty hệ thống thông tin FPT [Influence of company culture on employees' commitment to sticking: The case of FPT information system company]. Tạp chí Kinh tế \& Phát triển, 185, 119-127.

VietNam Report. (2016). Top 10 các ngân hàng uy tín nhất Việt Nam năm 2016 [Top 10 most prestigious banks in Vietnam in 2016]. Retrieved March, 12, 2019, from http://vietnamreport.net/Top-10-ngan-hang-thuong-mai-Viet-Nam-uy-tin-nhat-20165585-1036.html

Yildirim, S., Acaray, A., \& Candan, B. (2016). The relationship between marketing culture and organizational commitment: An empirical study in Turkey. World Journal of Entrepreneurship, Management and Sustainable Development, 12(1), 66-80. 